\title{
Questioning generational replacement. An age, period and cohort analysis of electoral volatility in the Netherlands, 1971-2010.
}

\author{
Electoral Studies 32(1): 37-47.
}

(c) Wiley Journals, 2013. SSCI Impact factor 0.714

\begin{abstract}
Political behavior has been changing all over Western Europe and electoral volatility is one of the facets of politics in which this change is apparent. Theories on stabilization of political attitudes and behavior in life time and the slow rate at which change in the electoral arena is found to proceed, have led to the assumption of generational replacement as the mechanism driving change. The Netherlands, however, provide a remarkably different case of this trend in electoral volatility. The country has shifted from an example of how cleavages stabilize politics to one of the most electorally volatile countries in Europe. The Dutch surge in electoral volatility thus contrasts with expectations of a slow process driven by generational replacement. Starting from this apparent contradiction between the evolution of volatility in the Netherlands and theories on generational replacement, this article investigates time effects of electoral volatility. The study is based on an age, period, cohort analysis on the repeated cross-sectional data of the Dutch Parliamentary Election Studies, 1971-2010. Based on characteristics of such repeated crosssectional data, individuals are cross-classified in birth cohorts and election years respectively, which overcomes the identification problem inherent in cohort analyses. Results of a crossclassified random effects model (CCREM) indicate that, contrary to the hypothesis of new generations causing the increase in volatility, the Dutch change can be attributed primarily to period effects. As such, the analyses indicate that a general shift in the Dutch electorate has caused the growth in volatility and that supply-side factors should probably be analysed when trying to explain electoral volatility.
\end{abstract}

\section{Keywords}

Electoral volatility; Age-period-cohort analysis; Generational replacement; Dealignment; Electoral change; The Netherlands 


\section{SUMMARY}

\section{Introduction}

Voting behavior in Western Europe has changed considerably over the last decades. The description of Lipset and Rokkan of frozen party systems no longer seems valid and the continued importance of cleavages for voting choices has been questioned (Franklin et al., 2009). Additionally, partisan dealignment is argued to have eroded the bonds between parties and voters and to have altered voting behavior in Western Europe. A cognitively mobilized electorate no longer bases its voting choices on partisanship or cleavages. Instead, voting choices have become subject to short-term factors and voting behavior has thus become more volatile (Dalton, 1984; Dalton, 2013; Dalton et al., 2000).

Empirical support for these fundamental changes in voting behavior has been accumulating in the last decade (Dalton et al., 2000; van der Brug, 2010). However, as is the case for most political changes, shifts in voting behavior proceed very gradually, which has led scholars to assume that a process of generational replacement causes these changes (Franklin, 2004; Hooghe, 2004; van der Brug, 2010; van der Brug and Kritzinger, 2012). A large and growing number of studies have already investigated the impact of generational replacement on changing political attitudes or political behavior (Franklin et al., 2004; van der Brug, 2010; van der Brug and Kritzinger, 2012). These studies, however, are faced with the challenge of a perfect linear dependency between age, period and cohort, preventing researchers from analytically distinguishing between these three time-related effects (Glenn, 1976; Mason et al., 1973; Yang and Land, 2006). Recently, Yang and Land $(2006 ; 2008)$ have drawn attention to the opportunities provided by pooled cross-sectional surveys to solve this time effects puzzle. In a repeated cross-sectional design, individuals can be cross-classified in period groups and cohort groups. This cross-classification breaks the linear dependency of age, cohort-membership and survey period for an individual. Using this method on cross-sectional data in political science, researchers have turned to testing whether the theories of generational replacement are accurate.

Several Western European countries have witnessed a trend of electoral instability over the last few years, but the degree to which the consequences of dealignment have become apparent differs from country to country. The Netherlands have been characterized as extremely unstable 
in comparison with what is observed across Europe (Mair, 2008). This is all the more surprising because the Netherlands were once an example of how cleavages structure voting behavior and thus stabilize a party system (Andeweg and Irwin, 2009). The Dutch party system is by now a very typical and almost extreme example of a volatile electoral setting, with recent Dutch elections ranking among the most volatile in Europe since World War II (Mair, 2008). This sharp increase raises questions on the validity of generational replacement theories to explain electoral change. Therefore, in this article, the time effects contributing to electoral volatility in the Dutch party system are investigated. To disentangle aspects of age, period and cohort related to generational replacement theories, a cross-classified random effects model (CCREM) iss developed on the pooled cross sectional data of the Dutch Parliamentary Election Survey (DPES), 1971-2010. This dataset includes representative election surveys for thirteen Dutch national elections since 1971.

The article begins with an overview of the literature on changing voting behavior and dealignment and more specifically on the mechanism of generational replacement driving political change. I will also elaborate on the exceptional position of the Netherlands in this matter and on why this specific case seems to contradict theories on generational replacement. Data and methods will be explained in section 3 and the subsequent two sections contain results and discussion.

\section{Change driven by Generational Replacement}

\subsection{Changing Voting Behavior}

Since the 1970s, an increasing number of studies have indicated that voting behavior in Western industrialized countries is in a state of flux (Dalton, 1984; Dalton et al., 2000; Pedersen, 1979; Rose and McAllister, 1986). These findings on change contradict the hypothesis of frozen party systems (Lipset and Rokkan, 1967). With their freezing hypothesis, Lipset and Rokkan linked the apparent stability of party systems in Europe to the role of social cleavages. In their view firm cleavages in society characterize and determine political conflict, leading citizens to vote according to their membership of social groups, as produced by the cleavage structure (Lipset and Rokkan, 1967). 
The thesis of cleavage-based stability has been challenged on a number of grounds. Shortly after Lipset and Rokkan had published their theory, the idea of stability was already considered out of date (Aarts and Thomassen, 2008). First, some studies pointed to the declining explanatory power socio-structural factors provide with regard to voting choices (Franklin et al., 2009). Second, the rise of 'new cleavages' and post-materialist issues in the electoral arena shows the demise of the cleavage model to explain voting behavior (Kriesi, 2010; van der Brug, 2010; van der Brug and Van Spanje, 2009). Furthermore, short-term factors such as campaigns and a focus on individual candidates are expected to become increasingly important in voting behavior (Dalton et al., 2000; van der Brug, 2010; Walczak et al., 2012). Although quite a few studies aim to counterbalance this tendency and continue to stress the relevance of social class, religion and other social cleavages for voters' party preferences (Brooks et al., 2006; Elff and Rossteutscher, 2011), it is clear that voting behavior is changing significantly.

Most studies assume that changes in voting behavior can be explained by invoking structural social changes, which do have an impact on the way citizens relate to the political system. The focus on wider changes in society as explanations for change in political behavior and attitudes is partly due to the central role that generational replacement has in the work of influential scholars such as Inglehart or Putnam (Alwin and McCammon, 2006). A number of scholars, however, focus on demand-side factors and on how institutional and political factors affect political behavior. As a compromise between both views, De Graaf and his colleagues (2001) suggest that an interplay between social and political factors drives change in voting behavior. Although political factors are clearly relevant as well, the fact that changes in electoral behavior are found across the industrialized world, indicates that specific institutional factors cannot be expected to be the main drivers of change. Rather, broader processes within society are likely to be causing alterations in political behavior found in a large number of countries (Dalton, 2013). Therefore, in order to understand what causes political volatility, the focus in this article is firmly on society, and more particularly on voters.

More generally, the bonds between parties and voters are argued to be eroding and fewer people identify with a particular party. This process of dealignment may well be caused by the electorate's cognitive mobilization. Thanks to educational progress, newer voters are better informed and more politically aware. Furthermore, most voters nowadays have the necessary 
skills to process an unprecedented amount of political information new media provide them with. These cognitively mobilized voters, then, no longer need the guidance of partisan cues when voting (Dalton, 1984; Dalton et al., 2000). Dealigned voters are thus more susceptible to influence from short-term factors on their political preferences. Therefore, their voting behavior is also expected to be less stable (Dalton et al., 2000).

\section{$(\ldots)$}

\subsection{Generational Replacement}

For different reasons, changes among the electorate are expected to be driven by generational replacement. First, a process of cognitive mobilization was expected to cause alterations in general and dealignment more specifically (Dalton, 1984), as has indeed become apparent over the last few decades. The role of education is crucial in this reasoning. Its importance in society has increased gradually, with levels of education rising from generation to generation. This in itself introduces an aspect of generational change. As a consequence, it can be assumed that electoral changes associated with this process of cognitive mobilization are also driven by a process of generational replacement. Second, individuals' political attitudes and their behavior are shown to remain quite stable in voters' lifetime. After a period of political socialization early in life, political attitudes and opinions tend to change more incrementally (Alwin and Krosnick, 1991; Jennings et al., 2009). Moreover, partisanship inheritance is found to be an important determinant of party choice, and high correlations are found between parents' and their offspring's party preferences (Jennings et al., 2009; Niemi and Jennings, 1991). Although these preferences are not unresponsive to short-term factors, parent influence and therefore stability of vote choices does not disappear completely (Niemi and Jennings, 1991). Third, theories on the formative years are an additional reason to expect a major impact from generations. The specific political and societal context in which citizens become politically socialized is expected to leave an imprint throughout their lives (Franklin, 2004; Plutzer, 2002). Fourth, political change is found to proceed very gradually. Changes in political attitudes, turnout or voting behavior are all small and they only occur step by step. Therefore, generational replacement is expected to be the mechanism driving change, with generation after generation becoming slightly different in political behavior from the previous one. As such, small changes accumulate and contribute to the alterations in political behavior that have lately been observed (Franklin, 2004; Hooghe, 
2004; van der Brug, 2010). With regard to declining turnout, the mechanism of generational replacement has been investigated and found to be apparent in quite a number of studies by now (Blais et al., 2004; Franklin et al., 2004; Gallego, 2009; Wass, 2007). For voting behavior as well, significant differences have been found in what explains the vote choices of different generations (van der Brug, 2010; Walczak et al., 2012).

Research on change over time is faced with the problem that different aspects of time are easily confounded. Although it is difficult to distinguish the effects of age, cohorts and periods, they do signify different aspects of change and point to distinct evolutions. Age can establish whether there are differences between young and old voters. Adding cohort effects can clarify whether such differences disappear as these voters become older or whether differences between groups of voters are expected to remain stable. Furthermore, period effects should inform us on whether all voters, regardless of their age or membership of a certain birth cohort are equally affected by change (Blais et al., 2004; Gallego, 2009; Wass, 2007). Analyzing these three time effects -age, periods and cohorts- for electoral change should therefore provide information about the longitudinal trend and can hint to what could be expected for the future. If only age effects are of importance, then life-cycle theories can explain differences between age groups. If so, then no over-time change is expected to be found unless the age distribution in a society changes fundamentally. Significant cohort effects would hint at the importance of the impressionable years, leaving an imprint on particular cohorts throughout their lives, and should indicate a gradual but accumulating change over time. Significant period-effects, finally, can indicate the occurrence of changes in electoral behavior driven by the specific time context affecting the whole electorate. Additionally, disentangled time effects not only provide a glimpse of the future, they also provide hints at which substantive indicators drive change. While cohort differences are associated with processes of broad societal change, period effects are assumed to reflect changes in the party system. Therefore, identifying the most important time effects can provide preliminary evidence on what causes increasing electoral volatility (Evans and Tilley, 2011; Jansen et al., 2011). The main question guiding the analysis, therefore, is to determine to which degree age, cohort or period effects are responsible for the observed rise in electoral volatility in the Netherlands.

\subsection{The Dutch Electoral Context}


Changes in voting behavior and increasing electoral instability have been found in several countries across Western Europe. The Dutch case exemplifies this overall trend: in the 1950s and 1960s, the Netherlands was still a model of the stabilizing impact of cleavage structures for political behavior (Andeweg and Irwin, 2009; Mair, 2008). As in other countries, the opening up of party competition and an increasing importance of short-term factors in vote choices and for election results had already been noted some decades ago. Traditional parties were losing grip on their 'heartlands' and had to convince voters by means of other arguments than that of traditional identification with a religious or social group (Irwin and van Holsteyn, 1989; van Holsteyn and Irwin, 2003). The decline in the importance of the cleavage structures for voting behavior in the Netherlands seemed to be driven both by societal and political changes (De Graaf et al., 2001; van der Brug, 1999).

In the current era, the Dutch electorate has become one of the most volatile in Europe, as is apparent from comparisons of aggregate volatility (Mair, 2008). The Pedersen indices for net volatility in Dutch elections since the Second World War, are presented in Figure 1. Furthermore, to allow for comparison, the Pedersen index for elections in a number of other West-European countries has been included as well. ${ }^{1}$ The graph illustrates the increase in volatility observed by scholars in the 1970s. With hindsight, however, the changes noted in the 1970s were not as important as was then thought. Elections after 1990 were much more volatile compared to those from the time before. Furthermore, a comparison with other countries highlights the trend of volatility in the Netherlands. Indeed, the Pedersen index for Dutch parliamentary elections has evolved from median to one among the highest in Western Europe. Figure 1 thus illustrates the claims made by Peter Mair (2008) with regard to the remarkable path followed by the Netherlands. Theories of generational replacement are generally substantiated by findings of slow changes in political behavior. The sudden increase in electoral volatility in the Netherlands, however, might indicate that other processes have caused political change.

\footnotetext{
${ }^{1}$ The countries included are Austria, Belgium, Denmark, Finland, France, West-Germany, Iceland, Ireland, Italy, Luxembourg, Norway, Sweden, Switzerland and the United Kingdom.
} 


\section{Figure 1. Pedersen Index of Net Electoral Volatility, the Netherlands in comparative}

perspective, 1945-2012.

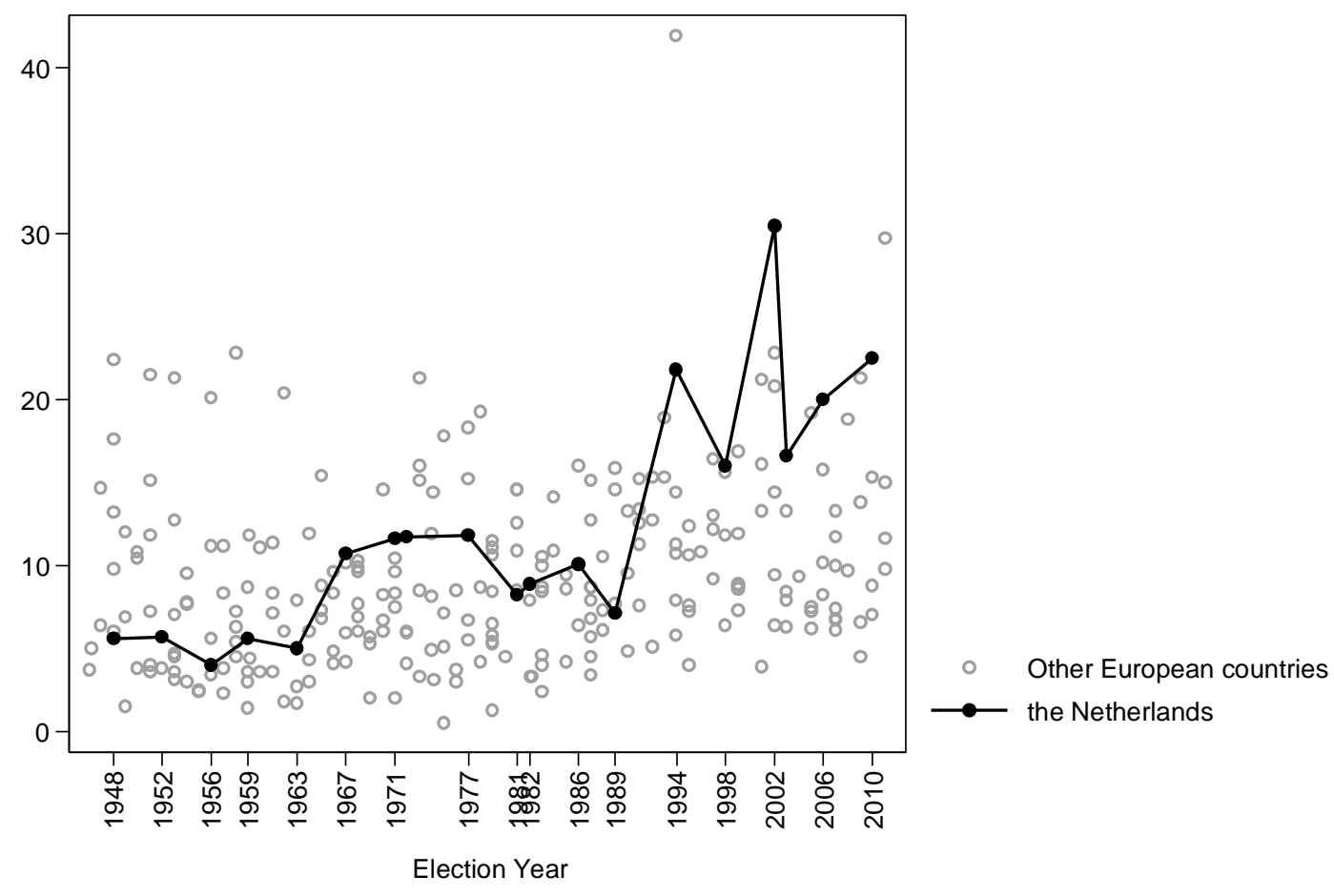

Pedersen Index of Aggregate Volatility in Dutch parliamentary elections. Calculated by summing individual parties' changes in vote shares from one election to another and dividing this sum by two. Source: Own calculations.

The decline of cleavage politics in the Netherlands has been investigated by a number of scholars. The process observed in the Dutch context is called depillarisation, referring to the erosion of structural cleavages in society and in politics more specifically (Lijphart, 1989). Due to the erosion of cleavages, electoral change and volatility now characterize politics in the Netherlands (Aarts and Thomassen, 2008; Irwin and Van Holsteyn, 2008; Mair, 2008). Moreover, the substantial increase in volatility has led researchers to scrutinize other factors than socio-structural ones. Peter Mair (2008) argued that the combination of weakening social cleavages and the easy accessibility of the Dutch electoral system resulted in the strong unpredictability observed.

\subsection{Hypothesis}


An increase in aggregate levels of volatility in the Netherlands has been observed from the 1970s onwards and evidence is still accumulating. This growing volatility and unpredictability of electoral behavior and election results is a trend which is apparent in a number of countries across Western Europe. Although these changes are mostly explained by processes of generational replacement, the sudden and sharp increase of volatility in the Netherlands suggests that other processes might be at work.

The apparent contradiction between theories on generational replacement and the pace of change in the Netherlands calls for an analysis of the time effects causing volatility in the Netherlands. Both general theories on electoral change and literature on depillarisation in the Netherlands link the changes with generational replacement processes. The sharp increase of volatility in the Dutch electorate, however, raises doubts about the idea of generational replacement as the mechanism causing volatility. Therefore, the hypothesis in this article is that besides generational change, the analysis will show that significant period effects are apparent as reasons for the Dutch volatility.

\section{Data and Methods}

The analysis is based on cumulative data from the Dutch Parliamentary Election Studies (DPES) of 1971, 1972, 1977, 1981, 1982, 1986, 1994, 1998, 2002 and 2006. ${ }^{2}$ Additionally, data from the 2010 Dutch Election Survey were included in the analysis. ${ }^{3}$ These data sources provide repeated cross-sectional observations of representative and random sample national election surveys in the Netherlands (Todosijevic et al., 2010). The entire dataset consists of data for 22,417 respondents, with between 1,526 and 2,623 respondents for each year. Although the election surveys were independent from each other, the cumulative dataset contains identical and harmonized variables for each survey (Schmeets and Van der Bie, 2008). As a result, the dataset is suitable for a longitudinal analysis of evolutions in electoral behavior over the period 1971-2010. Repeated cross-sectional data allow to analyze the effects of age, period and cohort in a single analysis despite identification problems (Wass, 2007; Yang and Land, 2008). Furthermore, a cross-

\footnotetext{
2 Data from 1989 were excluded because respondents were not asked to indicate their year of birth. As a result age and birth cohorts could not be calculated for 1989. Data for 2003 were excluded because of the panel-design for that year's election survey. The same respondents were interviewed in 2002 and 2003. As a consequence, a recallquestion was not included and the dependent variable could not be constructed in the same way as for the other election years.

${ }^{3}$ I am grateful to Henk van der Kolk (UTwente) for providing the data of the 2010 national election study.
} 
sectional design is preferred to panel studies because it does not suffer from panel bias due to varying attrition rates for each subsequent wave (Wass, 2007).

\section{$(\ldots)$}

\section{Results}

What time effects significantly contribute to the rise in electoral volatility in the Netherlands is assessed by means of a Cross-Classified Random Effects Model (CCREM). The probability of reporting volatile voting behavior in two subsequent parliamentary elections is estimated. Estimated logit coefficients and standard errors of fixed effects and variance components of the random effects are reported in Table 3.

In a first model (Model I), only time effects are included. Age is a fixed effect and birth cohorts and election years are specified as random. According to this model, there is a significant negative effect of age, indicating that party preferences remain stable throughout a person's life. ${ }^{4}$ With regard to the effects of cohorts and periods, the variance components of a model that only includes age as a fixed indicator, provide a first indication of the overall effect of both time elements (Yang et al., 2009). As can be seen from the lower part of Table 3, there is no significant variation in volatility between birth cohorts, but there is in election years. Furthermore the variance at the level of birth cohorts is estimated to be practically zero. These statistics therefore indicate that the increase in volatility noted in the Netherlands and apparent from Table 2 as well, is mainly driven by period effects and therefore by specific elections. While birth cohort effects are estimated to be virtually non-existent, there is substantial variation at the level of election years. Random effects of election years are not included in Table 3, but are graphically represented in Figure 2.

The next model (Model II in Table 3) includes additional socio-structural variables of gender, education, social class and religious denomination. It can thus be assessed to what degree these factors, linked to slow processes of change, are causing the increase in volatility in the Netherlands. A first finding is that men and women are not significantly different with regard to chances for volatility. Second, there are some effects of respondents' educational level.

\footnotetext{
${ }^{4}$ Additionally, the squared effect of age was tested to take into account a curvilinear effect of aging on volatility. This proved to be non significant and therefore only the main effect of age is included in the models.
} 
Respondents with a lower, secondary or higher level secondary education are more likely to switch votes compared to voters with only primary education. Voters with a university degree are not significantly different from respondents with only primary education. This finding might already confirm the curvilinear effect of political sophistication on electoral volatility described by other scholars, with highest levels of volatility among the group with an average level of sophistication (Kuhn, 2009; Lachat, 2007). Although voters' educational levels cannot serve as an exact measurement of political sophistication, they may well provide an indication of it or an association with it. Third, for social class, results indicate that those respondents who describe themselves as members of the upper class have significantly lower chances of switching preferences compared to the working class. Finally, there are some significant effects of respondents' religious denomination on electoral volatility as well. All groups, Dutch reformed, Calvinist, other religious groups and those without a religious denomination appear to be significantly less volatile in voting behavior compared to Catholic respondents, which is the reference category. This finding might be a reflection of several processes of secularization among various religious groups. Catholics were secularized first and fast. This may have led to less loyal voting and to more volatility in this group (Aarts and Thomassen, 2008). While the analysis indicates that socio-structural variables are relevant for explaining which voters are volatile and which voters are stable in their voting behavior, these variables do not explain change over time. The absence of cohort-effects already hinted at the limited impact of social change, and the variance components indicate that socio-structural elements cannot explain many of the period effects either.

Building on the previous model, Model III additionally includes political interest as a categorical variable in its analysis. The model thus allows us to test the assumption of a curvilinear effect of political sophistication on volatility, taking the form of an inverted U-shape with most volatility among citizens with an average level of political sophistication. This hypothesis does not hold for the present analysis, however, since those who report to be fairly interested in politics do not show significantly more volatile political behavior compared to those who report not to be interested in politics. Furthermore, including political interest as a categorical variable into the model can provide insights into whether cognitive mobilization is the mechanism causing the increase of volatility observed. As is clear from the variance components, however, including political interest does not explain change over time as reflected in cohort or election year effects. 
Table 3. Cross-classified random effects model of electoral volatility in the Netherlands, 1971-2010

\begin{tabular}{|c|c|c|c|}
\hline & Model I & Model II & Model III \\
\hline \multicolumn{4}{|l|}{ Fixed Effects (odds ratios) } \\
\hline Intercept & $-0.13(0.18) \mathrm{ns}$ & $-0.14(0.20) \mathrm{ns}$ & $-0.29(0.21) \mathrm{ns}$ \\
\hline Age & $-0.02(0.00) * * *$ & $-0.02(0.00) * * *$ & $-0.02(0.00) * * *$ \\
\hline Gender (ref. Male) & & $0.07(0.04) \mathrm{ns}$ & $0.05(0.04) \mathrm{ns}$ \\
\hline \multicolumn{4}{|l|}{ Educational level (ref. } \\
\hline \multicolumn{4}{|l|}{ Elementary) } \\
\hline Lower or vocational & & $0.23(0.08) * *$ & $0.23(0.08) * *$ \\
\hline Secondary & & $0.24(0.09) * *$ & $0.25(0.09) * *$ \\
\hline $\begin{array}{r}\text { Middle level vocational or higher } \\
\text { level secondary }\end{array}$ & & $0.18(0.08) *$ & $0.19(0.09) *$ \\
\hline $\begin{array}{r}\text { Higher level vocational or } \\
\text { university }\end{array}$ & & $0.10(0.09) \mathrm{ns}$ & $0.12(0.09) \mathrm{ns}$ \\
\hline \multicolumn{4}{|l|}{ Social class (ref. Working class) } \\
\hline Upper working class & & $-0.01(0.09) \mathrm{ns}$ & $-0.01(0.09) \mathrm{ns}$ \\
\hline Middle class & & $0.04(0.06) \mathrm{ns}$ & $0.05(0.06) \mathrm{ns}$ \\
\hline Upper middle class & & $0.01(0.09) \mathrm{ns}$ & $0.03(0.08) \mathrm{ns}$ \\
\hline Upper class & & $-0.48(0.17) * *$ & $-0.45(0.17) * *$ \\
\hline \multicolumn{4}{|l|}{ Religious denomination (ref. } \\
\hline Dutch reformed & & $-0.37(0.06) * * *$ & $-0.37(0.06) * * *$ \\
\hline Calvinist & & $-0.52(0.09) * * *$ & $-0.52(0.09) * * *$ \\
\hline Other religion & & $-0.33(0.12) * *$ & $-0.32(0.12) * *$ \\
\hline No religion & & $-0.25(0.05) * * *$ & $-0.25(0.05) * * *$ \\
\hline \multicolumn{4}{|l|}{$\begin{array}{l}\text { Political interest(ref. not } \\
\text { interested) }\end{array}$} \\
\hline Fairly interested & & & $0.14(0.06) \mathrm{ns}$ \\
\hline Very interested & & & $0.15(0.08) \mathrm{ns}$ \\
\hline \multicolumn{4}{|l|}{ Random Effects Variance } \\
\hline Cohort & $0.00(0.00) \mathrm{ns}$ & $0.00(0.00) \mathrm{ns}$ & $0.00(0.00) \mathrm{ns}$ \\
\hline Election Year & $0.32(0.14) *$ & $0.29(0.13) *$ & $0.29(0.13) *$ \\
\hline \multicolumn{4}{|l|}{ Goodness-of-fit } \\
\hline Log likelihood & $-6,642$ & $-6,597$ & $-6,595$ \\
\hline AIC & 13,292 & 13,229 & 13,227 \\
\hline $\mathrm{BIC}$ & 13,322 & 13,354 & 13,368 \\
\hline $\mathrm{N}$ & 12,018 & 12,018 & 12,018 \\
\hline
\end{tabular}

Logit coefficients reported for fixed effects, standard errors between brackets. Significance: $* * *<.001, * *<.01$,

*<.05. Method used: Cross-classified random effects two-level model in Stata. Source: DPES, 1971-2010.

Figure 2 provides an extra illustration of the effects election years on electoral volatility. In the graphs Baysian estimates of the effects of election years are presented as predicted probabilities 
(Yang, 2008; Yang et al., 2009). This concerns the net effects of the election years, as estimated in Model I, with the other variables kept at their means. ${ }^{5}$ As Figure 2 makes clear, election year effects are substantial. A strong, although non-constant, increase in volatility over time is obvious. Comparing different elections, the high probability for volatility in 1981 is noteworthy. From 1994 onwards, then, volatility is constantly at a higher level. The horizontal line in Figure 2 represents the overall intercept and indicates the divide in the period observed, with all elections after 1990 being more volatile than average.

Figure 2. Estimated election year effects - predicted probabilities of volatility

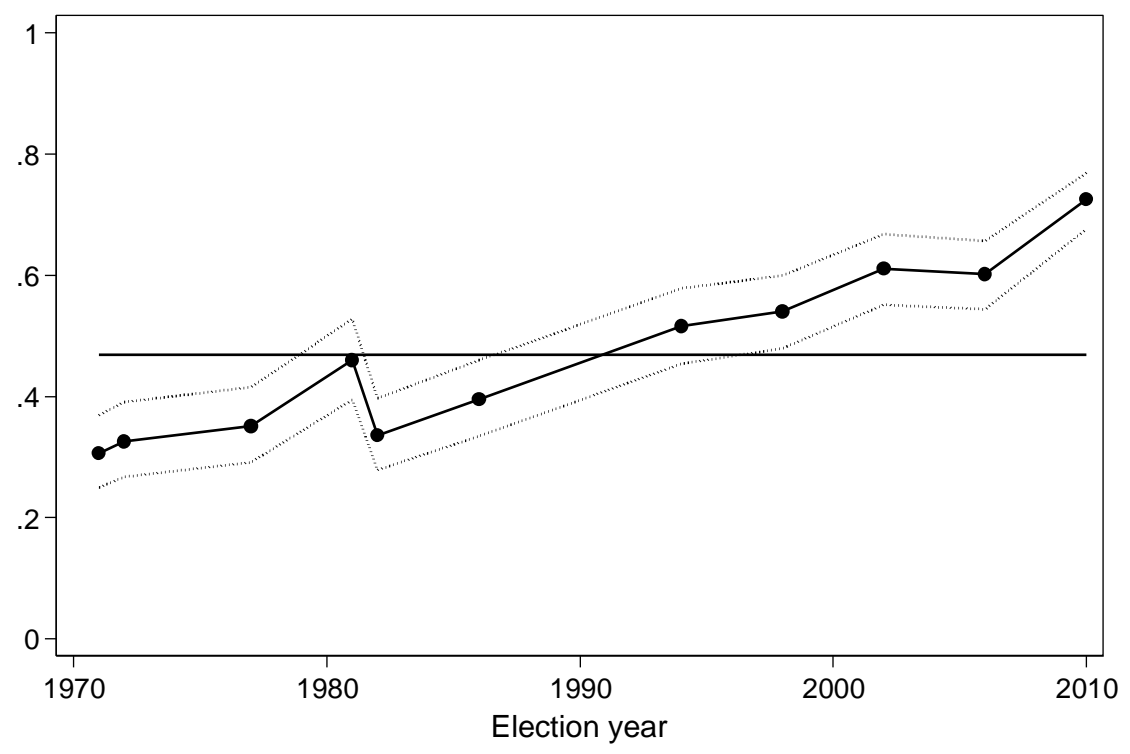

Predicted probability of volatility and $95 \%$ confidence intervals by election year. Bayesian estimates of random election year effects based on Model I in Table 3. Source: DPES, 1971-2010.

Besides an analysis of the variance components to assess overall effects of birth cohorts and election years on electoral volatility, an F-test can be performed. This is suggested to be a more reliable indication of overall effects, particularly in analyses with a limited number of periods or birth cohorts (Yang et al., 2009). F-tests are based on a comparison of log likelihood statistics for different models, in which no random effects, only cohort effects, only year effects and both

\footnotetext{
${ }^{5}$ The estimated effect is constructed from information on the estimated intercept and estimated random cohort effects. Coefficients are then converted into predicted probabilities.
} 
effects are included. ${ }^{6}$ The results of these tests for the analysis above including only age apart from the random effects, indicate that only period effects contribute significantly to an explanation of volatility differences. Adding birth cohorts does not significantly improve the explanatory power of the model. ${ }^{7}$ Therefore, the F-tests confirm the finding of the variance component analysis that change in volatility in the Netherlands is mainly driven by period effects affecting all birth cohorts equally.

Not only did volatility increase in the Netherlands over the period observed, turnout decreased at the same time (Andeweg and Irwin, 2009). One could argue that because the previous analysis of volatility is limited to voters turning out to vote in two consecutive elections, the effect of turnout can bias findings. Cohort effects in electoral volatility might not be apparent because the youngest birth cohorts do not (always) turn out to vote. In order to take this possibility into account, in another operationalisation of volatility, those voters who switch from not voting to voting or vice versa are also included as volatile voters. For this dependent variable as well, CCREM indicates no significant variance at the level of birth cohorts but a large and significant variance at the level of election years. ${ }^{8}$

\section{Discussion}

Political change is generally expected to be driven by a process of generational replacement. This assumption is based on findings of a strong stability of political attitudes and behavior throughout citizens' lives and because change is observed to proceed gradually. In the last few decades the trend toward increasing post-materialism in Western societies, for example, has been attributed to a process of generational replacement. Although the identification problem in cohort analysis hinders an assessment of the precise time effects, previous research seems to suggest that for changes in electoral behavior, a better understanding of these effects is important. The decrease of turnout levels in Western industrialized countries, for example, is found to be explained to a

\footnotetext{
${ }^{6}$ For a logistic regression the formula for the F-statistic, suggested by Yang et al. (2009), is: $\left(\left(1_{0}-1_{\max }\right) /(\mathrm{r}-\mathrm{m})\right) /$ $\left(1_{\max } /(\mathrm{N}-\mathrm{r})\right)$, in which $1_{0}$ is the $-2 \mathrm{LL}$ statistic for the fixed-effects only model, and $1_{\max }$ is the -2LL statistic for the model including random effects. $\mathrm{N}$ is the total number of observations, $\mathrm{m}$ is the number of explanatory variables at the first level and $\mathrm{r}$ is the sum of $\mathrm{m}$ and the number of cohorts and/or periods. For the null hypothesis of no effects to be rejected this F-statistic should be larger than the critical value of an F (r-m, N-r) distribution (Yang et al. 2009).

7 The F-statistic for the cohorts only effects is 0.47 , the statistic for the period effects only model is 4.60 and for a model with both random effects it is 2.51 . While the F-statistic for the period effects only model and the full model pass the critical value for $95 \%$ confidence, the F-statistic for cohorts only does not.

${ }^{8}$ Analysis on 14,655 cases, of which $36.12 \%$ were coded as volatile. Detailed results available from the author upon request.
} 
considerable degree by the entry of new generations into the electorate (Blais et al., 2004; Franklin et al., 2004; Wass, 2007).

With regard to voter volatility in the Netherlands, however, the sudden and strong increase of volatility contradicts theories of generational replacement. Therefore, significant period effects were also expected to cause the rise in volatility of the Dutch electorate. Results of the age, period and cohort analysis indeed showed significant variance at the level of election years. Moreover, no indications for a mechanism of generational replacement driving volatility in the Netherlands were found. Controlling for the impact of the three time-related effects (age, period and cohort), election years are noticeably the strongest predictors. The strength of period effects with regard to electoral volatility indicates that in the Dutch case all generations are affected by an increase in volatility. Furthermore, societal processes linked to composition effects or cognitive mobilization are not suggested to be causing the change either.

The importance of period effects in explaining increasing volatility is not only inconsistent with assumptions of generational replacement, it has some normative implications as well. Findings of significant and strong cohort effects would imply a hardly reversible increase of volatility over time. It would point at a mechanism of one cohort after the other reporting consistently higher levels of volatility. It would take the entry of several birth cohorts with consistently lower volatility to reverse the trend. The strong period-effect found, however, suggests that the increase in volatility is mainly caused by elections and contextual effects. Likewise, specific elections could decrease electoral volatility significantly across birth cohorts and age cohorts and this could therefore occur fairly rapidly.

The current findings, indicating that not generational replacement but cohort effects have caused the increase in electoral volatility, therefore lead to a new research question on the causal mechanisms of electoral volatility in the Netherlands. Given that period effects are strong, political actors and institutional factors should now be analyzed in research on the reasons for volatility. A likely culprit is the party system. If, for example, ideological distances between political parties have eroded, as is often claimed, voters would be more likely to shift from one party to another. This indeed would amount to a clear period effect as all voters, irrespective of their age or birth cohort, are equally exposed to this lack of a strong ideological profile among political parties. The media system too, might be a plausible candidate to explain period effects. 
Furthermore, the analysis above indicates that to investigate trends in electoral behavior, it is not warranted to focus exclusively on voters themselves, as that attitudinal shifts typically occur through means of generational replacement. Electoral behavior, however, is also determined by supply-side determinants, such as the strategy of candidates and political parties, the media context or electoral rules. Period effects are much more easily explained by such a supply-side approach than by assuming fundamental changes in attitudes among voters. Studies on changes in the link between voters and political parties, therefore should also take into account changes in political parties, party systems or media systems.

The result that cohort effects are much less important in explaining volatility than period effects are, raises a number of questions with regard to previous findings. It is remarkable that research on time effects explaining the decrease in turnout in Western Europe does find generations to be crucial. Since both are linked to the process of dealignment, one would intuitively expect the same time effects for both a decrease in turnout and an increase in electoral volatility. Therefore, the deviating results found for electoral volatility either signify that both processes are fundamentally different and caused by different processes over time or that different approaches to solve the identification problem distort findings considerably. For this reason, further research should clarify whether a CCREM-framework with regard to other aspects of dealignment, such as decreasing turnout, is consistent with what was found for electoral volatility.

The current analysis obviously suffers from some important limitations. First, it should be noted that the analysis is restricted to a single country. As stated above, the Dutch case is a highly exceptional one, because of the rapid transition toward higher levels of electoral volatility. This sudden increase already hinted at other mechanisms than generational replacement to explain change. It also meant that the Netherlands was a good case to study because of its obvious trend toward higher political volatility, a trend that is by no means clearly established for all Western democracies (Drummond, 2006). On the one hand it can be assumed that this provides us with ample empirical evidence about the alleged rise in electoral volatility. A counter-argument, however, might be that exactly because of its exceptional trajectory, the evidence from the Netherlands cannot be generalized to other Western societies, where the transition toward more electoral volatility occurred more gradually. Expanding the current research to other Western societies should inform us about whether these findings can indeed be generalized. Second, cross- 
sectional data were used in this analysis, which allowed to disentangle the effects of age, periods and cohorts. Making use of the advantages of cross-sectional data in order to estimate time effects, however, implied that recall data had to be used for the operationalisation of electoral volatility. Previous research shows that this type of recall questions is biased. At first sight, there is no reason to be overly concerned about this bias, because the recall questions are a fairly good reflection of real election results and because there is no reason to expect the quality of recall questions to change over time. As switches in party preferences over time can obviously be captured more reliably by means of panel data, a longitudinal panel data study of time effects on electoral volatility would be highly interesting. This would imply, however, that other approaches have to be taken to deal with the identification problem. Third, the analysis is limited to electoral volatility only. Therefore, further research is needed on the generational effects of dealignment, with attention for more indicators of this change in political behavior and with the inclusion of more countries to allow for a more substantive view on the evolution of political change in the Western industrialized world. 